\title{
Research on the Optimization of Physical Education Training based on Cross-disciplines
}

\author{
Wei Liu \\ Hunan Vocational College of Modern Logistics, Changsha, Hunan, 410131
}

Keywords: physical education; training method; cross-disciplines

\begin{abstract}
Physical education and training has always been the object of advanced deployment and priority support for colleges and universities and sports education and training, and it has the comprehensive advantages of adaptability and cross-study in talents, disciplines, funds, and equipment. This study selects the optimization of physical education and training cross-disciplines in China as the research object, hoping to provide references for the enrichment of interdisciplinary theory and the improvement of related scientific research systems. With literature research methods, conceptual analysis methods, expert interview methods, and other research methods, this paper aims to conduct comparative research on the basis of in-depth understanding and analysis of subject structure setting and professional division and setting, aiming at reviewing the cross-discipline of different disciplines and at the same time reviewing our country's physical education. The history and status quo of the development of training disciplines eventually settled in the analysis of the discipline development characteristics and laws of physical education and training.
\end{abstract}

\section{Introduction}

At present, based on the development of China's physical education and training research, scholars have a common understanding: that is, the complexity, intersection, and diversity of physical education and training disciplines. The trend of cross-disciplinary and multi-dimensional development of the century's physical education and training discipline has become an indisputable fact that the physical education and training disciplines have studied and witnessed by all of us. However, it is regrettable that the current situation and the future direction of the development of cross-sports disciplines have not been further analyzed in detail in the study of physical education and training disciplines. Even if there is a so-called crossover, it will only stop at the results of other disciplines. Research paradigms to carry out cross-disciplinary research and analysis. In academic research, the cross-study of physical education and training is still relatively weak, and there is no study from the practice to study the structural relationship between disciplines and disciplines, but also from physical education and training. The theory of cross-disciplinary research and the actual operation of physical education and training disciplines have been systematically studied and discussed. Therefore, this paper hopes to re-understand the discipline structure of physical education and training by analyzing the theory of cross-discipline to correct and optimize our physical education and training. Study the misunderstandings or deficiencies of the discipline structure to promote the integration and symbiosis of sports discipline structure.

\section{Current Situation and Problems in the Study of Physical Education and Training Cross-disciplines in China}

The research method refers to the discovery of new problems or new theoretical basis or means in research. It occupies a very important position in scientific research. Scientific and advanced multiple research methods can often determine the authenticity and objectivity of research results, and to a certain extent reflect the level of scientific research in the development of disciplines. "There is no research method that can reveal everything [1]. The broad argument must be multidisciplinary." As a typical cognitive activity, physical education and training is still indispensable to the use of research methods in its subject research. The author through the search 
for the year's sports education and training professional master's thesis, selected the collection of the four colleges of physical education and training professional postgraduate master's thesis selected research methods, found that the physical education and training research method is mainly used The speculative and empirical research uses a single method of questionnaire survey and is limited to descriptive and macroscopic research. It mainly focuses on the literature method, questionnaire survey method, mathematical statistics, logic, and other methods. Fewer, the research method is simple; the research work of physical education and training can only stay at a low level.

At present, China's sports discipline belongs to the first-level discipline under the category of education. In the secondary disciplines, the sports subject is divided into four secondary disciplines, including physical education and training, sports humanities sociology, national traditional sports, and sports human science. Such division criteria and subject ownership all have the disadvantage of mutual inclusion. Physical education and training includes sports and pedagogy, sociology, biology and other disciplines in the form of vertical and horizontal cross [2]. If physical education is placed under the category of education, it cannot correctly reflect the status and nature of the discipline of physical education. In the second-level discipline classification, physical education and training, national traditional sports are based on the application of different dimensions of the core as the subject group; sports humanities and society is composed of the discipline group and humanities and social sciences intersect the subject group; sports human body science It is a cross-disciplinary group composed of natural sciences and sports disciplines such as medicine and biology. This discipline structure serves as the basis for the professional training of sports doctors and masters in China, which leads to inaccurate career orientation of high-level personnel training in sports majors and the unclear relationship between curriculum systems.

With the development of society, more and more talents are getting more and more people's needs. However, in our school physical education curriculum, physical education and training is often based on teaching and research rooms, for example, the Track and Field Teaching and Research Office, the Ball Teaching and Research Office, and the Gymnastics Teaching and Research Office. Etc., etc.; the design of teaching content also follows the pre-determined model of the experts. This leads teachers to turn into "machines" that simply teach course content. Students also passively accept it, resulting in the most valuable course content resources. The experience of teachers was wasted. The teachers of the teaching and research sections are also behind closed doors. There is a lack of regular communication platform among the disciplines. In the direction of the discipline, they are basically self-constructed and imitative. They are each other, and there are scientific research resources between disciplines, teachers, and students. The problem of mutual blockades makes it difficult to carry out cross-disciplinary research [3].

\section{Factors Affecting the Inter-disciplinarity of Physical Education and Training}

The intersection of disciplines has become an important trend in the development of contemporary science and technology. However, at present, the management level up to the school, down to the average teacher, still has a certain gap in the subjective recognition, does not pay attention to the mutual reference with other related disciplines, the limitations of the researchers themselves, disciplines The relatively thin cross-awareness leads to insufficient motivation for the development of disciplines. Furthermore, because of the relative freedom of university teaching, college teachers are highly qualified individuals as a group of high-level intellectuals. Many teachers are influenced by traditional academic backgrounds and research contents and perspectives. They like to be behind a closed door and stick to their own technical expertise. They are reluctant to change the thinking and inertia of single-discipline studies, and do not open up new disciplinary spaces. Therefore, the lack of communication among many scholars has become extremely difficult, resulting in lack of corresponding initiative and originality in research [4].

The teaching and research sections of sports institutes in our country are mostly set up according to special projects or certain applications. This is more easily demonstrated than the teaching and research sections of other disciplines. It is easier to form "knowledge wall" and "discipline wall" at the same time as it is conducive to the organization and planning of teaching work. The physical 
education teaching and research section has formed its own unique mature, stable and independent value identification, research field, research horizon and research direction in its teaching and research practice activities. It is easy to form factionalism and portal disputes and seriously blocks the interaction of information, sharing of resources, academic exchanges, and scientific collaborations have constrained the development of teachers; while promoting the rapid development of specialized sports disciplines, they have brought discipline integration, interdisciplinary research, and cross-disciplinary talent training in the sports field. The spell curtailed the pace at which sports science took off again. Most of the organizations are teaching and researching in the form of teaching and research rooms. It also affects the development of interdisciplinary studies [5].

\section{Research on Optimization of Physical Education and Training Subjects}

A good atmosphere will help organize researchers in different disciplines to conduct regular exchanges and ideological collisions and refine major scientific issues so as to promote the active academic atmosphere. Just like the laws of nature, disciplines gradually form certain rules in their own fields of development, and regulate the influence of other disciplines by this rule. The mutual integration and interpenetration of various disciplines has become the main way of scientific knowledge innovation. . Professional ledges hinder the intersection between disciplines and are not conducive to the development of disciplines. In the cultivation of interdisciplinary talents, disciplines must follow the law of development, breaking professional barriers to meet the needs of discipline development. Therefore, it is important to strengthen the connection with the parent discipline and pay attention to the construction of basic disciplines. Physical education and training is a comprehensive course with a strong professional theory. It has a close connection with basic disciplines. For students in schools, grasping the basic disciplines can promote the physical education and training courses. Learn.

In the new historical period, we believe that the concept of "academic freedom" should be permeated in the teaching and research of colleges and universities. It is based on the essence of education and studies the teaching with forward-looking eyes, that is, the teaching and research in universities must be based on the nature of education. We will study the standardization of education and teaching laws, the goal of talent training, the innovation of discipline construction, the rationalization of curriculum settings, the enrichment of teaching content, and the diversification of teaching methods and means. 1 Under this concept, discipline-oriented, in accordance with the principle of hierarchical management, center of gravity downwards, responsibility and equivalence, and symmetry of resource functions, a new type of basic, discipline-based, research-led, and academic-leader-oriented Teaching and scientific research organizations.

Facing the current era of knowledge explosion, can colleges and universities cultivate the key factors to meet the urgent need of talents in the society: one depends on the characteristics of the discipline and the other depends on the quality of the discipline and specialty. Faced with the oversupply situation between employment units and college graduates, the employment pressure for college graduates is increasing. As the saying goes, "material is rare," and under such circumstances, employers have become more and more demanding on talents, and conditions are getting higher and higher. The education under market economy also requires universities to train professionals to be market-oriented. The ultimate goal is to solve the graduates' employment problems and increase the employment rate, so as to achieve the combination of the professional structure of the university and the market demand structure. Therefore, physical education and training should focus on strengthening the connotation of disciplines, as well as strengthening and improving the construction of professional characteristics and innovation. To protect the overall level of professionals as a fundamental, to improve the knowledge structure of graduates as a means to enhance the quality of graduates as a means to promote the social adaptability of graduates for the purpose of vigorously improve the connotation of professional disciplines, promote professional construction Only when innovation, specialization, and flexibility are integrated can we enhance the competitiveness of universities. To cultivate the talents that society really needs. 
In order to achieve further achievements in physical education and training in our country, we must first establish and improve the disciplinary system, democratic discipline management system and discipline development policy system, of course, the role of the organization of professors, expert committees and other organizations is not to be underestimated. Under the new situation, the discipline construction of physical education and training in China needs further improvement and innovation. Because the impact of the planned economy era on China's sports disciplines is deeply entrenched, the talents that have led to the training of the discipline structure of physical education and training disciplines in China are subject to many rules and regulations, which make the subject construction impractical, knowledge learning is limited, and the discipline innovation consciousness and ability The discipline has been severely curtailed. Such a discipline model has caused serious imbalances in the disciplines of sports training in China, especially with extremely bad influences on the intersection of disciplines. Such a system, such an environment not only hinders the progress and development of disciplines, but also makes it difficult to develop interdisciplinary innovative talents that are compatible with social development. This requires the development of sound disciplinary policies to solve these problems. It is imperative, for example, to improve the cross-cutting development of traditional disciplines, to set up new disciplines, and to formulate a reasonable proportion of disciplinary structure and layout policies so as to maintain sustained and harmonious development among disciplines. Can find a place in the socio-economic development.

\section{Conclusion}

The scientific research level and characteristics of universities are all reflected in the disciplines. Cross-discipline construction also becomes an extremely important task of the university accordingly. More people turn their attention to the study of disciplines and subject structure. Therefore, this article has a certain theoretical and practical significance. However, the discipline optimization problem related to physical education and training cannot be solved by a small paper. Due to limited capabilities, there are still many problems that need to be further explored and improved. For example, research on the development trend of the discipline structure at home and abroad is not yet in place. It is incomplete to analyze the problems existing in the cross-disciplinary disciplines of physical education and training in China. At the same time, the article proposes physical education. The feasibility study of training science and related countermeasures to optimize its interdisciplinarity have yet to be tested and demonstrated in practice. The answers to these questions are all motivating me to continue to explore in this field.

\section{References}

[1] Jin Wulun. Incommensurability: scientific progress and crossover scientific paradox [J]. Innovation and Technology. 2007 (11)

[2] Lu Changfen, LUO Qinpeng. Discrimination of Sports Science, Sports Science and Sports Disciplines [J]. Journal of Tianjin Institute of Physical Education. 2009 (04)

[3] Wang Cangle, Ruan Chong, Chen Ruiqin. The Role of Interdisciplinary Research in Sports Science Innovation [J]. Journal of Shanghai Institute of Physical Education. 2009 (04)

[4] Lu Changfen, Yang Wenxuan, Luo Xiaobing. Analysis and Adjustment Suggestions on Classification of Sports Subjects [J]. Journal of Physical Education. 2009 (04)

[5] Tan Guang, Ma Weiping. An Analysis of the Characteristics of Postgraduates Majoring in Physical Education and Training [J]. Sports Culture Guide. 2009 (01) 